\title{
About the Symbiosis Mother-Child in Adults: Discussion on the Endotherapy Taboo
}

\author{
Giuliana Galli Carminati1,2 (D), Federico Carminati2,3 (D) \\ ${ }^{1}$ Seoul National University (Bundang Hospital), Seoul, Republic of Korea \\ ${ }^{2}$ International Society of Multidisciplinary Psychoanalysis, Geneva, Switzerland \\ ${ }^{3}$ Physicist at CERN, Geneva, Switzerland \\ Email: giuliana.gallicarminati@gmail.com
}

How to cite this paper: Carminati, G. G. \& Carminati, F. (2020). About the Symbiosis Mother-Child in Adults: Discussion on the Endotherapy Taboo. Psychology, 11, 1067-1080.

https://doi.org/10.4236/psych.2020.118070

Received: June 10, 2020

Accepted: August 4, 2020

Published: August 7, 2020

Copyright (c) 2020 by author(s) and Scientific Research Publishing Inc. This work is licensed under the Creative Commons Attribution International License (CC BY 4.0).

http://creativecommons.org/licenses/by/4.0/

Open Access

\begin{abstract}
This paper discusses the possibility to accept in individual psychoanalysis (or sometimes psychotherapy) two members of the same family by the same analyst, with particular attention to the "dyad" mother-adult child. We examine the history of the strong interdiction of this practice in the psychoanalytical doctrine and we argue that there are situations where this practice is not only acceptable but very beneficial to the patient, and indeed to both members of the dyad. When the mother-adult child relationship is fusional, the therapist can act as "third" entity by creating two private spaces (the two therapeutic settings) that introduce a first separation between the two fusional elements. We introduce the term endotherapy for this, indicating the "insertion" of the therapist "from within" the fusional couple to provide some leeway to both mother and child to ease a stressful and energy-wasting emotional situation. The clinical case of a fusional dyad between mother and daughter is presented where this practice has helped into alleviating the fusional state and the tensions and has allowed the daughter to progress in her adult life.
\end{abstract}

\section{Keywords}

Mother-Child Psychoanalysis Mother-Child Psychotherapy, Mother-Child Fusional Relationship

\section{Introduction}

Among the guidelines often mentioned in psychoanalysis and strongly held as normative, is the ban to accept the mother and the adult child in individual psychoanalytic therapy by the same analyst. It is difficult to establish precisely the historical origin of this ban. In 1905, Freud wrote that the psychoanalysts were 
"compelled to pay as much attention in our case histories to the purely human and social circumstances of our patients as to the somatic data and the symptoms of the disorder" (Freud, 1905: pp. 25-26).

However, in successive writings, Freud expressed the conviction that it was counterproductive and even dangerous for a therapist to get involved with more than one member of the same family (Freud, 1912, 1915), referring in particular to the treatment of the male-female couple by the same analyst. Little is said of other members from the same family (for a discussion see Gurman \& Kniskern, 1981: p. 16; Goldenberg \& Goldenberg, 2007: pp. 150-151).

This negative opinion, although partial and circumstantial, has become practically a postulate among analysts, who have accepted it in an acritical manner and with the force of a real dogma. In 1938, a study of British analysts revealed that, almost without exception, they were accepting the ban on analyzing members of the same family (Glover, 1955) and that only a minority believed that mitigating circumstances could exist. In 1956 even an analyst as innovative as Kubie (1956) wrote: "The simultaneous analysis of husband and wife (...) can be very useful if it is carried out independently by two analysts".

The taboo has been partially overcome with the development of psychoanalytically oriented family therapy, and this ban has been held responsible for the delay in the development of a solid analytical theory of family therapy (Bowen, 1975; Broderick \& Schrader, 1991; Glover, 1955). Despite the considerable developments in psychoanalytic family therapy, many analytical schools still consider the ban on treating members of the same family in individual psychoanalysis by the same analyst as an unsurpassable ethical principle, without questioning neither its origins nor its absolute value.

The motivation for this ban, however, if not its absolute and acritical acceptance, is not completely devoid of reason: the psychoanalyst should maintain a neutral attitude towards reality and focus on the description of it conveyed by the patient. In other words, the psychoanalyst tries to keep the "objective reality" (as much as such a thing exists) at a distance to avoid his ${ }^{1}$ own interpretations of the analytical material to be influenced by it and, further, influence the patient's individualization process (Jung, 1916a, 1933). The "further" is emphasized, because the psychoanalyst's unconscious will inevitably get entangled with the patient's unconscious (Baudouin, 1950).

We touch here a veritable "bush of brambles" where any approach leads to a painful sting. Already the definition of psychoanalysis is very difficult to differentiate that of psychotherapy. Even the concept of cultural psychoanalysis remains ambiguous, because it would seem almost impossible to separate the knowledge of the unconscious from the action on the unconscious (which is indeed largely unknowable). In Psychology and Alchemy, Jung (1944) writes: "Consciousness can be trained like a parrot, but not the unconscious. If physi-

${ }^{1}$ To avoid overloading the text with "his/her" every time we refer to a patient or a therapist, we use the masculine gender, but of course our text refers equally to male and female patients and therapists. In the clinic case we use the female gender. 
cian or patient errs in his interpretation, the unconscious, working always autonomously, corrects them strictly and uncontradictably in time".

The Swiss psychoanalyst Charles Baudouin (1950), who did not have the academic qualifications to call himself as a therapist (Baudouin, 1920: IV, p. 146), but who certainly was a great one with a large therapeutic experience, defines three therapeutic levels. According to him, these are interchangeable according to the needs of the patient, which should remain the focus of the therapist:

- Psychoanalysis: from the unconscious of the therapist to the unconscious of the patient;

- Suggestion/hypnosis: from the conscious of the therapist to the unconscious of the patient;

- Cognitive-behavioral therapy (for which he minted the term "psychagogy"): from the conscious of the therapist to conscious of the patient;

According to this schema, psychoanalysis, hypnosis, cognitive therapy, (auto) suggestion and psychology form a continuum with the patient and the therapist at its centers, like the two foci of an ellipse. If we accept this definition, the rather "fluid" boundaries between psychoanalysis and psychotherapy encourage us to reconsider also the rules of psychoanalysis and psychotherapy as a continuum, ideally non-contradictory, of indications to be considered with the patient's well-being as the only guide. In this context, we would like to re-examine the possibility and the role of the simultaneous individual psychoanalytic treatment of two members of the same family by the same therapist. This should not be considered in general, but rather in special cases where this may prove to be an effective strategy for the patient(s).

\section{The Concept of Endotherapy}

In our clinical experience these cases have common characteristics and require a specific strategy that we would like to identify with the term endotherapy. By this term we mean a therapy in which two patients of the same family are treated by the same therapist simultaneously but separately. This differs from systemic therapy, even if sometimes in systemic therapy the therapist or patient(s) may request a personal session. With this term we express the intervention of the therapist to unravel a bound that is so tight and fusional that it is best approached "from within" with the simultaneous but separate treatment of both individuals sharing this bond by the same therapist. If we accept psychagogy (in the sense explained above) as part of the therapeutic "continuum", we necessarily open the door to interferences from the "real" and not just the "subjective" reality of the patient, also in the context of psychoanalysis, that, according to the vision of Charles Baudouin, we can hardly separate from the other therapeutic paths.

The reason for devoting our attention to this topic is that in our clinical practice we have observed several of these fusional mother-child dyads. These are difficult cases, not easily treatable with classical psychoanalysis and impervious to psychotherapy. The fusional aspect of the mother-child relation prevents the 
child to operate a working transference onto the therapist, so strong is the loyalty conflict with the mother. Moreover, these patients are in a state of great suffering for the continual conflicts with the mother, which leads them to a state of mental and physical exhaustion. The psychical energy trapped in the conflict is such that these patients have difficulties to devote enough attention and energy to their life, with possible failures in the relational and work domains. Our primary motivation is therefore to find an effective way to help these patients to make enough progress, creating a small hiatus between them and their mother, to be sensitive to other kinds of therapy, be it a classical psychoanalysis or a support psychotherapy.

Indeed, the patient's struggle to separate from the dyadic mother is terrible and relentless. It absorbs almost all the energy of the individual, who can invest only a few things, and only at the margins of life, in the form of narrow, almost autistic interests. Even a professional activity may be impossible, with failure neurosis and a total inability to find one's place among colleagues. The emotional life of such individual, if not sexual - also very complicated, when present - is nonexistent. The other is "stupid", uninteresting. The greatest pleasure is to go home and "close the door", no partner around, finally alone ... phew!

Sexual activity is reserved to the parents, mother or father, whatever (and this is weird: "whatever"), there is an undifferentiation between the male or female sex, too close to the source of life; the primitive scene, in any case is prohibited and frightening. The identification of the person implicated in the mother-child dyadic symbiosis as person with a gender (whatever that is) and a sexual inclination (again, irrespectively of whatever this is) is a hard journey for the patient, but also for the analyst.

We believe that this is a field that would deserve more attention. Our experience shows us that these patients do not know very well themselves which gender they belong to. The "separating third element" (usually the father) failed to separate them and everything seems blocked at the oral phase or maybe barely the anal one. We surely do not reach the genital phase. Sometimes some sexual intercourse (hetero/homosexual) is possible, but we have the feeling that these attempts are "experimental", almost from outside of oneself, as if they were not really there. It is not the eternal sex/love duality, it is like an outsourced sexuality, like companies that outsource work, without investing it with the company's spirit.

One of these patients, very subtle in his analysis and endowed with a very piercing insight told me about Cybele, before the divine gesture which emasculates her under the blade of Dionysus, according to certain legends, when she is a monstrous being, female and male, before Demeter, but without the mythical wisdom of the Rebis (Evola, 2006: p. 279; Jung, 1916b).

\section{The Parental Imagos}

Let us recall here a concept that we have elaborated in a previous work: "In therapy, much has been said and written about the different therapeutic me- 
thods, schools and strategies. We believe that what is important in therapy is the therapeutic withdrawal. The great difficulty of the therapist is to avoid intervening too much, or better, even when it is necessary to intervene to concretely support the patient, to allow himself and the patient to experience voids, silences, pauses where nothing happens, and nothing is important. A "rewind of time" back to the mother-child-dyad, with all its splendor of damped noises and calm... this pristine calm of very early childhood. If, for some reason, we have not experienced this mother-child dyad, we are missing this original frame of reference, to the point of preventing us from advancing in life. We may be unable to face the next step, that of the introduction of third, confronting it with attack and/or seduction, to finally be able to turn away from the parental couple and look elsewhere for a social life, a new partnership and start the life cycle again, or, if this is not our destiny, to constitute ourselves as adults" (Carminati et al., 2018).

When we speak of withdrawal, the passivity in therapeutic non-action, this could appear in contradiction with the very fact of meeting and talking with, say, the patient's mother. The point here is that such patients, being completely unable to differentiate who or what, remain entirely included or bound in the maternal dyad and the world remains far, really too far beyond their horizon. These patients, so engulfed in the dyad, are and remain in troubled waters. Here we can say that therapeutic withdrawal that is not shared is not a withdrawal: if the therapist contents itself with observing the patient's turmoil and the only outcome of his withdrawal is to increase the patient's restless confusion, the withdrawal has no therapeutic value.

Both Freud and Jung recognize the importance of the interiorization of the primitive impressions of our parents. Freud gives them the central role in the edification of our psychical apparatus via the CEdipus complex, while Jung makes them fundamental archetypes and the origin of the parental complexes. We can say that the superego takes the aspect of parental imagos, that in our practice we call "little mom and little dad", which are the representation of the real parents of a young child who depends on them completely and can die from their abandonment. The child is confronted by giants that are five times his height, incomparably strong, all powerful, who know everything, understand everything and, he believes, can read his mind. Their judgment is final. We would even be tempted to write "little mom-little dad" with a dash indicating the non-separation of the two entities. Long after having introduced these entities in our practice to describe the parental imagos, we discovered that "little mother" and "little father" are the terms with which the people called the czar and czarina of Russia.

These imagos are obviously not Mr. and Ms. Smith, with their complex humanity: to be able to "see" them as such, the development of the individual must progress far enough to allow "little mom" to be separated from the individual in question with the help of "little dad", to allow the individual to leave the parental imagos, now profitably introjected, and to orient himself towards society by 
starting his adult and sexed life. For these patients, on the contrary, it is almost impossible also to separate the parents, let say, to separate little mom from little dad, everything is mixed. The little dad only has a definite connotation bolding the line, making a parody of him, and it remains an image almost not differentiated from little mom. It does not exist as a separating third entity, but it is seen as an appendage of mom, sometimes subject to the power of the mother, sometimes violent and abusive, or indifferent, or absent. In any case inadequate.

The inability of the patient/child to separate mom from the whole reality leads to a singular attitude: everything is kept, or everything is thrown away: the patient alternates between a Diogenic accumulation and a total "garage sales" attitude, to finally make room. Management more balanced that "all-or-nothing" seems impossible to achieve for money, objects and goods in general. Same attitude toward knowledge, it is necessary to know "everything" otherwise nothing is known. This makes it very difficult to move from theory to practice, to make the "big step" of the "small step" with which the journey starts, to accept compromises with reality.

Integrating "little mom", therefore separating her from reality, would already be a step forward, then, if the "third" is finally glimpsed, the father can be "integrated" and, thanks to "integrated little dad", we arrive, more or less, to separate little mom from little dad, another step forward. Then we it will be time to leave the family cocoon and look at the world. A arduous journey for these patients. In addition, there is no daylight between "little mom", the parental imago, and "Ms. Smith" mother of the patient. The patient describes his mother as a two- or three-years old child could do. She can everything, knows everything, nothing can escape to her. The patient must tell her everything that is going through his head, because anyway she will know. As if she could read thoughts, no lie can be admitted.

When I dare pointing out to these patients that everyone is lying, or at least hiding part of the truth, and that truth, is so ephemeral and difficult to define that its very existence can be doubted, the patient's surprise is real and not feigned. When I suggest that Ms. Smith, as any human being can also lie, the reaction is almost outraged. Unfortunately, and it often happens, Ms. Smith may have been psychologically or even physically abusive. So, if mom beats me, since she never lied, it was me who has been wrong, "a shit", useless, mean. Beware of the therapist who tries to re-inflate the injured self: if the therapist thinks that I was not at fault, it is my mother who was unjust, and this cannot be. The whole patient's psychical structure risks to crumble. But if the sentiment of injustice is often removed, rage and pain still smolder under the ashes.

The concern is that, my patients being adults, Mr. and Ms. Smith have grown older and beginning to decline in health and strength. The patient, who lives in a deep, and mostly unavowed, hatred and who sees all the family meetings turning into fights, does not know how to avoid being hurt, again and again, without giving up his feelings or hurting his aging parents. A sentence that I find in all the stories of my patients who live in a situation of unresolved symbiosis is: "She 
(my mother) picks on me, she knows the exact sentence to say to make me explode. I reacted by insulting her, everything went down the drain. I almost hit her (or I hit her, or she hit me), I was furious." This discourse is almost pathognomonic of the unresolved symbiosis, much more present than in the couple's conflict where there are certainly similar repetitive patterns, but often with less psychological and more physical violence.

\section{The Introduction of the Separating Element}

The patient seems to be unable to put even a small distance between his psyche and that of his mother. Lying is impossible, as we said, so no room for maneuver. The patient cannot say "yes, yes" to the mother and carry on with his life, like all adult children learn to do with their old parents. The patient is naked, exposed to the all-powerful and awfully vicious mother.

Let's open a parenthesis here. We have repeatedly stated that the patient in symbiosis seems unable to find a minimum of leeway in lying. We also said that it is the introduction of the third party, the father, who represents/brings the law, which should help in separating the child's from the mother's psyche in the mother-child dyad. But lying is the very contrary of the law introduced by the father, so we are in apparent contradiction. Or maybe not.

The rules of the father and that of the mother are different in nature, mother's frustration and father's law are not the same. The mother "knows" if you have transgressed, and you have no way to atone. Like in the movie "Dreams" of Kurosawa, when the little child watches the fox marriage, the mother "knows" because Nature itself told her. The deed is done, and the mother tells the child to commit suicide abandoning him to his fate. The father punishes you, but only if you are caught. He is mighty but not omnipotent. The Spartan youths in the agōge were given too little to eat. They were "expected" to steal food, and they were "supposed" not to be caught, this was part of their training. But if they were caught, they were harshly punished, even to death, because they violated the law of the state. If we see this in the space of the archetypes, we use the True/False archetype to split the Nurture/Culture one. Or rather, we never really separate anything, since what enables our psychic life is the possibility to oscillate between the two opposite poles of the same archetype.

The point is that Ms. Smith, without excluding a real perversion, which sometimes certainly exists, is often neither omnipotent nor awfully vicious. She is often a woman who had big troubles when she gave birth to her child, did not know what to do, had gone through a difficult delivery that had left her on her knees (but god forbid she admits that, otherwise she could be accused to be a failing mother, just think about the taboo of the cesarean), she had trouble in breastfeeding, had couple concerns, or did not have a couple at all, the father of the child being literally or figuratively absent, had an unbearable mother-in-law, an absent mother, few friends, a strong postpartum depression, she slept poorly and was very worried. And sometimes all of that together. So, she became abusive through exhaustion, confusion, lack of intelligence, loneliness, fear. 
In our clinical experience we see various combinations of these situations in the patients' mothers. And if we go a little further, we often find dramatic stories of child abuse by the grandmother of the patient, histories of family mistreatments and suicides. Often, all of this, which belongs to previous generations, is partly or totally unknown by the mother of the patient who only has the "official version" that she was given in her childhood, via obscure anecdotes, platitudes, without real memories. Her abhorrence of lies is because she knows, consciously or unconsciously, that she has been lied to and truth may be irrecoverably lost. Her frequent obsession with cleanliness is because she feels there is "dirt" in corners she will never reach, and she will never clean. Certainly, real perversion exists, there are crazy or criminal parents who cruelly beat their children, lock them in the cellar, abuse them, give them neither food nor care... but often symbiotic mothers are and/or have been mostly helpless women.

The father was too external to the mother-child dyad, or too preoccupied with bringing in his salary, or was drinking, or was sick, or he had run away, or he was really dead, and the mother had not enough resources to overcome the situation, to have the psychological availability necessary for the child. The child saw in his mother's eyes fear, suffering and sometimes mental illness, or death (Green, 1980; Estellon, 2013). To save his mother, a child uses all his strength until he is exhausted and all but nothing of his energy remains. This desperate struggle creates an intimate dyadic bond that will affect the child for the rest of his life.

Indeed, the analyst, when the symbiosis is too "primitive" and the suffering too great, can meet Ms. Smith (Mr. Smith also if necessary) and position her in the reality of the patient. No matter what is said in this or these interviews, the therapist attests that there exists a reality in which Ms. Smith exists and evolves, without the patient, a reality which is validated by the presence of the therapist. If then Ms. Smith wants to engage onto the therapeutic path, why not? The difficulty is to, at least consciously, keep the two therapies separate (no passage of information), although the unconsciouses are in communication through the therapist's one. But, again, why not? Essentially the therapist is called to play the role of third-party separator, secretly, in withdrawal, if we want to reuse this term. We recall here that in the context of systemic therapy, the $2^{\text {nd }}$ cybernetics tells that the therapist is part of the system that is being cared for, but in this context the discussion on family dynamics is done in the presence of the individuals from the same family (Becvar \& Becvar, 1996; Albernhe \& Albernhe, 1999).

So here I am, the therapist, in front of the mother, if and when she has been convinced to see me. I thank her for being there and listen to her talking about her life, in withdrawal. And from time to time I ask a few questions, I continue to listen and above all I reassure her about her qualities as a mother, always. Because I have the right to lie (and after all I don't have even to lie, it is enough for me to change my angle of observation) and I can create this other reality my cabinet and her story told to me between the two elements of the dyad. For the 
patient in symbiosis with his mother and who cannot lie, the big problem is that all of his thoughts must/can be seen by his mother, without any possibility of escape, not even for one instant, from maternal control. Any removal, any failure, any lie, omission, hypocrisy is sanctioned by abandonment and therefore death.

The story the mother tells the therapist can be quite superficial. She often recites the "official version" of her child's childhood, the encounter with her child's father; sometimes a few secrets emerge. Notwithstanding, what is important is this time spent to talk, even without saying anything. This creates a bubble of secrecy to which the child can relate to, just because this bubble exists and is not his mother only, but something other than his mother, a "secret" she shares with the therapist. A split between their psyche's looms.

Whatever she says which I of course keep to myself are words that allow the third party to finally insert itself into the dyad, because the mother learns that by separating from the child the child will not die, as I assure her about this, and, as in a mirror, the child knows that he can move away from his mother because she too will survive her madness, as I assure the child about this.

As we said above, it is not possible/thinkable for these patients to say "yes-yes mom" and then to do as they please. This is even beyond the will of Ms. Smith, who is often not so comfortable with the tense and aggressive loyalty of her child and who often does not understand his posture. The mother finds it unbearable, of course, to be confronted, but especially to be confronted with outbursts of anger that she finds disproportionate, obviously not realizing her own outbursts. The symbiotic mother is often a "simple" person, direct, practical, well anchored in "her" reality. I dare say that often she presents a frustrated personality with little or no ability to analyze herself and her feelings.

Often this mother is a child who lived in symbiosis with her own mother, and she herself was an abused child, insecure, with low self-esteem, apart from being convinced to have very important and desirable qualities of honesty. To put it simply, she often reproduces the pattern of her childhood in the childhood of her child, with utmost rigidity and loyalty to the parental pattern.

The bubble created in the exchange between therapist and mother makes it possible to detach the two psyches, even via a very thin gap, because there is another space; there is, like we just said, an attempt at the introduction of the third, a loophole. Sometimes the mother's therapeutic journey does not stop at the first two or three interviews: the mother feels need for a therapy and chooses to continue this with her child's or with someone else. It is entirely possible, and it could be a wise solution.

\section{A Clinical Vignette}

Patricia is a woman between 40 and 50 years, a hardboiled single, tall, graying, with a short "helmet" haircut, fairly dry, always soberly dressed, never in heels, with an explosive laughter. She works in scientific research, her position is prestigious, and her place assured, she lives alone with her four dogs and two cats.

She says she has already benefited from two psychotherapies, three years each, 
and wants to start a psychoanalysis to better understand herself. She says she feels the root of her problems escape her and she wants to understand and change. Her intellectual level is very good, she has an excellent academic curriculum and qualifications. Relationally she was in a four years relationship, more than ten years ago, with a young American man very close to his own mother. This relationship remained at the level of a teen romance, without common life, engagement or marriage. He returned to the USA where he now lives with his mother and aunt.

She enthusiastically announces hating pink, disliking the company of her female congeners, preferring the company of men who otherwise do not seem to be very interested in her, to regret. She says that she feels lonely, but also that she is very satisfied of her single life, free to do whatever she pleases. In fact, not much, as her mother dismantles all her projects because they are expensive or dangerous or useless.

Patricia announces at the outset that she never wanted to have children, as to settle the matter once and for all, and nevertheless she opens every other session with wise philosophical tirades about overpopulation, the need for autonomy and the pleasures of freedom. Indeed, she lives 1500 meters from her mother and her whole life revolves around the relationship with her. In spite of the "self-evidence" of her situation, it will take a long portion of her analysis to get her to admit that indeed, her fierce claims of independence from men have their roots in the fear of her mother's judgment on them the day they are presented to her so, to avoid quarrels and disappointments, nothing better than celibacy.

The mother's judgment is felt and experienced as absolute: first she has to tell her what she wants to do, then, faced with her criticism, Patricia feels obliged to react with a nervous tantrum instead of keeping her plans to herself or may be starting a polite discussion followed by effectively doing what she wants. There is a prodigious lack of distance between herself and her mother, the reciprocal being, at this point, less clear.

During our sessions we "go in circles". Patricia directs the dialogues, delivers well-prepared speeches, seems unable to shut up or to listen, keeps reviving childhood memories. Talking about childhood is necessary in an analytical process, unless these memories are used more like a family album to show than a way to evoke authentic feelings. Sometimes I would like to ask her why she continues this psychoanalysis, so strong and ingrained seems her desire to change nothing-nothing-nothing.

It seems that her emotional life froze when she was 10-12 years old. The father, about whom little is said and practically only at my request, divorced from the mother when Patricia was six years old. He remarried and started another family, but the patient never saw her three half-brothers. The mother did not want to remarry and had short relationships without ever living together with her partners, in her words, "to dedicate herself entirely to her daughter".

Patricia happily describes her vacation with her mother and, as we said, she never talks of the father; she likes to remember the holidays in the kindergarten 
or the nursery. She also speaks much of her mother's family, sometimes of her paternal grandparents. She conveys the feeling of a joyful childhood, with some rare sentences about her mother's harsh education, her mother of course, founding her "difficult", even unbearable.

The sessions follow one another much in the same patter until Patricia announces that she has renounced going to a conference in Japan because her mother considered the country too far away. Patricia, angry after a violent fight with her, delivers a poignant cascade of confessions ranging from mistreatment by her mother, who corrected her physically until she was 20 , to her conviction that her mother is not well. She also confesses her anguish of aging, her continual frustration for the lack of attractiveness she exerts on men and her feeling of emptiness, all in a stream of tears.

At the following session, Patricia claims to have given up the congress in Japan because she is against whale hunting and wants to mark her protest stand. She again talks to me again about her satisfaction in living alone and free, without children and fully enjoying her life as a single. I feel that it should not be pushed, the ice has reformed on the lake of the unconscious, let's stay there for now. This internal struggle exhausts Patricia, literally torn between the fear of seeing her mother sink into a psychic illness, which she suspects, and the fear of sinking herself into a depressive decompensation.

A few months after the cathartic/confessional session, talking again about her childhood, I suggest to Patricia that indeed her mother told her in her own way her vision of things and that probably she was not comfortable herself as a mother, the divorce having plunged her even more in her relational and emotional difficulties. Patricia is extremely surprised, almost offended at the idea that her mother had to "tell her [things] in her own way" instead of just "telling the truth" and, at my statement that everyone is lying, so her mother too, she almost interrupts the session. I do not retain her, and for good measure I add that she should stop seeing her mother with the eyes of a little girl.

"Your mother, I insist, sensing her hurt but receptive, is a woman with her qualities and her faults who did what she could, like everyone else, maybe making big blunders, but finally nobody is perfect." Patricia ends the session with a more than thoughtful air and I wonder whether she would come back. The sessions are interrupted by a vacation period and Patricia returns with a slightly changed attitude. She tells me about her plan to buy a liftback, she can drive but never had a car before, to travel with her dogs and asks whether I could meet her mother in session, to assess her status. Patricia is about her getting older, she could feel her getting lonelier and tired. I suggest I will think about it and give her an answer soon.

I am reluctant to take this step because, as we saw above, meeting people in the entourage of a patient in psychoanalysis, and especially the mother, is almost taboo, and much more so starting a therapy with them. It's true that Patricia as embroiled in a loyalty conflict towards her mother that deeply engulfs her, so unshakable, primary, primitive and constitutive is their bond. I feel like Patricia 
and his mother are united by a spring and any attempt of one of them to move away pushes them even closer to each other, to resume their endless violent "domestic disputes" and moments of unstable appeasement. Anyway, I accept.

Patricia's mother arrives at the session with the firm intention to obtain justice for the insolence of her daughter. I smile and ask her to tell me a little bit about herself because I know that she had a full and complex life. Ms. Smith (we'll call her so) starts talking about her homeland, Russia, her family and her mother, a peasant woman married at a very young age to a much older man, widowed still young and with six children to feed.

Ms. Smith wanted to study veterinary medicine, but how to do that with so little money? Life brought her to Switzerland, where she married, but life was not easy with Patricia's father and they divorced. Patricia's father had left to work in Bern and her bond with her and her daughter had frayed. For years and especially after his remarriage he had hardly given any sign of life. Ms. Smith seems happy to tell me about her life and offers to bring pictures for me "to get to know her better". I accept and during the next three sessions we watch pictures of her family, Patricia as a child, a young girl and a young adult.

"Do you think that my daughter is psychologically disturbed?"

"Not at all, she is very intelligent and capable and loves you very much. She has excellent position in her work, and everyone appreciates her."

Ms. Smith smiles with such a relief that almost surprises me. We talk about not becoming a grandmother, given Patricia's celibacy and age, Ms. Smith sees no problem with that: "Patricia always wanted to study, it's her life", she replies. This beginning of therapy, or rather this brief encounter, is interrupted because Ms. Smith, very thrifty, finds the sessions expensive and does not want to charge her insurance of "unnecessary" costs. I understand that it came from her desire not to go any further and preserve her fragile structure. So be it.

Patricia manages to hold back her curiosity, more because of her fairly long therapeutic experience telling her that I was not going to say anything than for sincere discretion. She contents herself with the idea that her desire to find support in me "against" his mother was granted.

The work of psychoanalysis is of course unfinished, there is much more to revisit: the link with her father, a more serene vision of sexual and relational life, a possible emotional investment in a couple relationship, if desired, the mourning for what life could not, did not want or had not been able to give her. Patricia shows up at a session before summer with a very elegant blouse with pink flowers. Of course, I do not say anything, staying quiet and silent is also a good (and prudent) way of lying.

\section{Conclusion}

We come back here to the theory of this contribution. In the secret space or bubble of endotherapy, lined with good intentions, sentences of decorum, skirting around everything that causes conflict and behind closed doors, each one 
can express her hope and find some leeway. I insist that knowing that somewhere we have the sacrosanct right to have recourse to lying is the basis of psychic survival. Allowing ourselves and our parents to lie leaves behind us the lost paradise of symbiosis but leads us to an oasis of well-being. In this bubble, the mother and the child also project their desire. The mother is convinced that I will scold her child who mistreats and abandons her, the child is convinced that I will tell her mother some hard truth. Both are confident that I will do justice, finally, that I will say what that it is necessary to say so that the truth can emerge and free them. A bit like in these movies where the cathartic dialogue is filmed from afar, with background music, and not a word is heard.

It is a literary device that we appreciate in thrillers, where we understand without knowing, which is much better than knowing without understanding.

We believe that the psychoanalytic profession should move beyond the rather ill-justified interdiction of mother-child treatment by the same therapist. However, while this, as we have tried to argue, is possible and even necessary in some situations, it remains a delicate exercise that requires special attention to the complex transfero-counter-transferential field that is created. In this sense it would be important that more colleagues could join the reflection on this subject, defining more precisely the theoretical framework, the conditions of applicability and the best practices to adopt.

\section{Addendum}

When I asked Patricia for permission to publish this vignette, she in turn asked me to add this to our text.

I was thinking of reading this at another time, but the curiosity was too strong! ... It must be said that I just had an argument with her... (my mother). And then, I wanted to know what my psychoanalyst thinks of me..., what she "sees" in me. So, I replied:

"Well let's be honest, it's not easy ... and it "almost hurts"! There are passages which made me cry, others made me laugh ... out of sadness. Anyway, I still have a lot on the plate of my psychoanalysis ...

Obviously, I will have to re-read and re-read again all this in order to understand it, and especially to possibly be able to talk about it with her (my psychoanalyst) ... It makes me afraid and happy at the same time to know that I will be able to see her for a long time ... because there is still a lot to do ... unfortunately ... before I feel completely released! ...

Let's say is a "long haul job", ... but it's worth it.

In psychoanalytic friendships

Patricia

\section{Conflicts of Interest}

The authors declare no conflicts of interest regarding the publication of this paper. 


\section{References}

Albernhe, K., \& Albernhe, T. (1999). Les thérapies familiales systémiques. Paris: Masson.

Baudouin, C. (1920). Carnet de route VI, Lorsque l'enfant paraît (Octobre 1918-Décembre 1921). Berne: Bibliothèque Nationale.

Baudouin, C. (1950). De l'instinct à l'esprit. Bruxelles: Desclée de Brouwer et Cie.

Becvar, D. S., \& Becvar, R. (1996). Family Therapy, a Systemic Integration (3rd ed.). Boston, MA: Alleyn and Bacon.

Bowen, M. (1975). Family Therapy after Twenty Years. In S. Arieti (Ed.), American Handbook of Psychiatry (Vol. 5, 2nd ed.). New York, NY: Basic Books.

Broderick, C. B., \& Schrader, S. S. (1991). The History of Professional Marriage and Family Therapy. In A. S. Gurman, \& D. P. Kniskern (Eds.), Handbook of Family Therapy (Vol. 2, pp. 3-40). Philadelphia, PA: Brunner/Mazel.

Carminati, F., Demongeot, J., \& Galli Carminat, G. (2018). L'attention flottante du poisson. Les Cahiers de la SIPsyM, No. 2.

http://www.sipsym.com/images/CahiersSIPsyM/N02-AttFlottantePoisson.pdf

Estellon, V. (2013). Du Complexe au Syndrome de la "Mère Morte". Les Cahiers du D.E.P.S.

https://lescahiersdudeps.wordpress.com/2013/05/13/du-complexe-au-syndrome-de-lameremorte-vincent-estellon/

Evola, J. (2006). Métaphysique du sexe. Lausanne: L’Âge d'Homme.

Freud, S. (1905). Three Essays on the Theory of Sexuality (1905). The Standard Edition of the Complete Psychological Works of Sigmund Freud, Volume VII (1901-1905): A Case of Hysteria, Three Essays on Sexuality and Other Works (pp. 123-246). Hogarth Press in London in 1953-1974.

Freud, S. (1912). The Dynamics of Transference. The Standard Edition of the Complete Psychological Works of Sigmund Freud, Volume XII (1911-1913): The Case of Schreber, Papers on Technique and Other Works (pp. 97-108). Hogarth Press in London in 1953-1974.

Freud, S. (1915). Introductory Lectures on Psychoanalysis (Part I). The Standard Edition of the Complete Psychological Works of Sigmund Freud, Volume XV (1915-1916). Hogarth Press in London in 1953-1974.

Glover, E. (1955). The Technique of Psychoanalysis. Baillière: Tindall \& Cox.

Goldenberg, H., \& Goldenberg, I. (2007). Family Therapy: An Overview. Boston, MA: Thomson Brooks/Cole.

Green, A. (1980). The Dead Mother. In A. Green (Ed.), On Private Madness (pp. 142-173). London: Hogarth Press. https://doi.org/10.4324/9780429478024-8

Gurman, A., \& Kniskern, P. (Eds.) (1981). Handbook of Family Therapy (1st ed.). London: Routledge.

Jung, C. G. (1916a). L'âme et le Soi: Renaissance et Individuation. Paris: Albin Michel.

Jung, C. G. (1916b). Psychology of the Unconscious. Eastford, CT: Martino Fine Books.

Jung, C. G. (1933). Modern Man in Search of a Soul. Abingdon-on-Thames: Routledge.

Jung, C. G. (1944). Psychology and Alchemy. Abingdon-on-Thames: Routledge.

Kubie, L. S. (1956). Psychoanalysis and Marriage. In V. Eisenstein (Ed.), Neurotic Interaction in Marriage (1st ed.). London: Tavistock. 